\title{
Contradictions, Impossibility, and Triviality: A Response to Jc Beall
}

\author{
Sara L. Uckelman \\ Durham University
}

\section{Introduction}

Orthodox Christian theology is full of peculiar little puzzles of interest to logiciansCan God create a stone so large that he cannot lift it? Can God know what it is like to be ignorant? How can God be identical with the Father and be identical with the Son, but the Father not be identical to the Son? How can free will and God's omniscience be compatible? Must that than which nothing greater can be conceived exist? Must it exist necessarily? These puzzles (some might call them paradoxes) challenge traditional approaches to logic because of the crucial ways that they all involve some notion or conception of 'contradiction'. For instance, if God can do anything, then he can create anything, so he can create a stone that he cannot lift. But because he is omnipotent, he can lift any stone, including the stone so large he cannot lift it-a contradiction. A notion central to orthodox Christian theology-the Trinity-patently seems to contradict the laws of identity (which are often considered to be part of the laws of logic itself).

A variety of different solutions can be (and have been) proposed to tackle these contradictory or potentially-contradictory settings, but rarely in a way that provides a global solution for all the problems. Instead, individual solutions are propounded for each of the paralogisms.

The present paper is a response to Jc Beall's "Christ-A Contradiction: A Defense of Contradictory Christology", in which Beall outlines a solution to a particular theological problem - the problem of attributing contradictory properties to Christ - that while being presented as a particular solution to a particular problem can nevertheless be generalized to some (perhaps all!) of the other "paradoxes" mentioned above. Beall's aims in his paper are two-fold: (1) "to illuminate the role that logic itself plays in theology" (401) and (2) to defend the view that "the true Christology is logically contradictory" is "both viable and motivated" (402), and that the only way to accomplish these two aims is through the adoption of a logic that admits contradictions, that is, a paraconsistent logic (and specifically, First-Degree Entailment, FDE).

Those who are familiar with Beall's work as a logician will not be surprised that this is the conclusion he reaches: He has long been an advocate for non-classical (and specifically sub-classical) logics where the classical rule of ex contradictione sequitur quodlibet "from a contradiction anything follows" does not hold. Nontheological reasons for adopting such paraconsistent, non-classical logics are well

Journal of Analytic Theology, Vol. 7, June 2019

10.12978/jat.2019-7.180000200213

(c) 2019 Sara L. Uckelman • (C) 2019 Journal of Analytic Theology 
rehearsed in other places (including Beall's own paper presently under discussion which provides many relevant references), and I will not spend much time on advocating for-or against-them here.

Instead, my purpose in this short discussion piece is to address a topic that he doesn't explicitly address, namely, "What is a contradiction?". Motivating why this question is important, answering it, and showing the consequences of the answer to Beall's project will be the central contribution of my paper.

In addition to this, though, I will also take a closer look at how Beall approaches his two aims. First, I comment on what he says is the role of logic within theories (theological or otherwise), and why-he thinks - this should lead us to adopt a logic that allows us to admit contradictions. Then, I put the spotlight on how logicians prior to Beall have dealt with these same issues in their attempts to solve the Christological and other theological problems. ${ }^{1}$ These issues-the relationship of logic to theology, and the ways in which we can accept classical Christology without devolving into irrationality or triviality-were core issues considered by medieval European logicians in $12^{\text {th }}-14^{\text {th }}$ centuries, and resolved in very similar ways. So we will in our investigation come to similar conclusions: For what Beall has to say, in essence, is not new, even if the details of his proposal are.

\section{What is logic? The role and nature of logic}

Before addressing the question of what the appropriate logic for reasoning about theological paradoxes is, Beall says something about what logic is and what role it is supposed to play (both in general and in theology). In his paper, Beall tackles these problems in reverse: first he outlines what he sees to be the role of logic, and then he goes on to say what logic in fact is. If this seems a bit backwards to the present reader, they should know that they are not alone; for in general we seek to identify what things are before we determine what their use or purpose is.

Beall sees logic primarily as a tool for the generation and maintenance of theories (scientific or otherwise). His account of the role of logic in theory generation and maintenance provides him with a rather narrow space into which he can define logic so that it can fulfill that role. The purpose of logic according to Beall is to identify what truths "follow from" other truths, given an explication of "follows from" via the notion of a consequence relation, which leaves very little space for what logic can be, if this is the role it is to play. Logic, according to Beall, is

a very special consequence (entailment, closure) relation. Logic is the common core of all (closed) theories; it is at the bottom of all the (extra-

\footnotetext{
1 Medieval attempts to reconcile the contradictions inherent in theology were not limited to the Christological contradictions alone: These contradictions are a part of a broader range of theological contradictions. There is nothing special or specific about the Christological contradictions-any solution that works for them should also work for the other thorny theological issues, and vice versaand in fact it is these other problems that exercised medieval logicians more than the Christological problems
} 
logical, theory-specific) consequence relations of our true theories (405).

where 'consequence (entailment, closure) relation' is taken in the way that Tarski defined it (fn. 6), along with all the technical constraints that come along with such a definition.

A brief aside: Beall argues that the importance of logic is that without the consequence relation(s) given by logic, "our theories remain inadequate; they fail to contain truths that are entailed by the given set of truths" (404); that is, they are incomplete (in the technical, logical sense of the word, in which every truth can be derived from the theory). Two things to note about this: First, while it is undeniably true that consequence relations are an important part of logic, it doesn't follow that this is the only thing logic is/does. It is also important to note that this need not be the case; for one could simply adopt a theory that contained every truth, relieving it of any need for an entailment or consequence relation, since every truth entailed by some truth in the set would already be in the set. But such a theory doesn't come without a price: For without having some entailment relation-or some other means of churning truths into other truths-it is not clear how we could generate or enumerate the truths of our theory. Such a system would be complete, but it would not be terribly useful. Therefore, the reason why we need an entailment or consequence relation is so that we can generate our set of truths from a finite-or finitary - set of basic truths. End aside.

As a logician myself, I found Beall's description of 'logic' rather peculiar, for it does not resemble any definition of 'logic' that I would provide (although what he defines as 'logic' is certainly a component of what I take logic to be, I do not want to deny that). There are a few things that should be noted about defining logic in this way. First, as noted above, if the role of logic in a given theory is to explicate what are the non-theory-specific consequences of the initial truths of the theory, then there is little else that logic could be other than the explication of a consequence relation: Make the purpose or use of logic narrow, then logic itself will have to be narrow enough to fit that purpose.

The upshot is that Beall's presentation of 'logic' sets up something of a strawman: What he describes as 'logic' is in fact an idiosyncratic version of 'propositional logic'. This reflects a specific view about the ontological status of logic. Beall clearly thinks of logic as an object of study, whereas a more fruitful way to think about logic is as a field of study. The definition that Beall gives is something that very few logicians would assent to, and requires a narrow, monist view of logic-and even logical monists don't think that propositional logic is the epitome of logic. This narrow definition of logic falls out of a narrow definition of its role or use. A broader account of the purpose of logic will allow us to give an alternative, broader, account of what logic is.

There is another reason why should prefer an alternative account of logic. If we look to the history of logic, it becomes clear that Beall's very narrow conception of 'logic', wherein it is nothing more than the most general consequence relation available, makes much of what has been called logic in the past no longer logic. (Some people might say this is a good thing; but one should worry about the suitability of a 
definition of a phenomenon that excludes much of what has historically been taken to be a part of that phenomenon, without some independently motivated reason for excluding those other parts, and an explanation for why history has gotten things so badly wrong. Neither of these two things are forthcoming in Beall's paper, and in fact when he approaches some historical questions raised in the "objections" section of his paper, attributing this narrow view of what counts as logic to historical theologians leads him into problems, as we'll see below.)

Let us consider a specific historical account of the nature of logic, one that does not resemble Beall's definition very much at all, but typifies an approach to logic that was dominant for more than a millennia and a half. Writing around 1250, Bacon says in his Art and Science of Logic that

logic, as a science, is the habit of distinguishing what is true from what is false by means of rules or maxims or dignities by which we can comprehend the truth of a locution through our own efforts or with the help of others. And logic is so-called from 'logos', which means discourse, and 'lexis', which means reason or understanding-as it were, the science either of reason joined to discourse or of discourse joined to reason $[4, \llbracket 3]$.

Bacon's definition highlights four important features of (the study of) logic:

1. It is aimed at distinguishing truth from falsehood.

2. It is rule-governed.

3. It can be a joint venture.

4. It involves discourse.

This provides a much wider scope for what can-and should-count as logic, which is determining truth using rule-governed methods, focusing on what is in fact true, and built into a cooperative, dialogical setting. In what follows, what we have to say about logic is to be placed against this more general conception: Logic is a set of practices or activities which are truth-seeking-and thus involve logical consequence-but also potentially involve other features.

With this alternative account of the nature of logic, I'd like to say a little bit about how Beall views its role. Recall above that Beall thinks logic's most important purpose is to generate and maintain theories via a notion of "follows from", explicated in terms of a consequence relation. Interestingly, nowhere in Bacon's account is a notion of consequence or entailment or closure mentioned. This is not merely because modern logicians have developed different terminology than what Bacon used, but for a more pathological reason: because there wasn't yet a concept for some alternative terminology to pick out. ${ }^{2}$

\footnotetext{
${ }^{2}$ Regardless of whether someone might respond to this point by saying "well, they should have had this concept (of logical consequence), and if they didn't, then they failed," the point still remains that the discipline of logic thrived for more than a millennia without an articulation of the concept that Beall
} 
This is because a general notion of "following from" or "what follows from what" was something that was only first begun to be articulated in the $12^{\text {th }}$ century, and was still in the process of being articulated in the $13^{\text {th }}$ and $14^{\text {th }}$ centuries. For many centuries logicians had been able to provide rules of inference governing limited sets of logical consequences (e.g., Aristotelian categorical syllogisms; limited propositional logic due to the Stoics; hypothetical syllogisms in Boethius; etc.), but one of the remarkable aspects of the developments of logic from the $12^{\text {th }}$ century onwards is that they can be understood in the context of people developing an understanding of a notion of "logical consequence" broader than the syllogistic, and then attempting to codify an informal and not well defined notion of "what follows from what". Until one has a general notion of logical consequence, in the sense that Beall wants to identify with 'logic', it is impossible for this concept to play a substantive role in the generation of our theories.

More importantly, the fact that a general notion of logical consequence or entailment wasn't developed until around the $12^{\text {th }}$ century has substantial consequences for some of the claims Beall makes in his paper. Throughout, Beall speaks of "Conciliar Christology", without ever being explicit what this is. Christology is, of course, the study of the properties and actions of Christ; but the "Conciliar" adjective derives from the grounding of these properties and actions in the so-called "conciliar texts" (402). These texts are the ones that resulted from the ecclesiastical councils in the early Christian era, and most specifically the Councils of Nicaea, Constantinople, Ephesus, and Chalcedon in the $4^{\text {th }}$ and $5^{\text {th }}$ centuries, where the Church Fathers set much of what is considered orthodox theology today. Thus, when we move back to the era of the ecumenical councils that first articulated the Contradictory Christology that Beall is supporting, we are now many centuries before the medieval logical developments we have been discussing.

When Beall asks:

Why would the conciliar fathers not flag their special-and undefined-usage of (for example) 'incomprehensible' and 'comprehensible' ... if they didn't intend the usual entailments to hold? (420)

this rhetorical question anachronistically assumes that there was some sort of "usual entailment relations" that the church fathers (a) were familiar with and (b) intended to hold. But neither of these are warranted assumptions. Logic-in both my and Beall's use of the term-was simply not sufficiently developed the time of the councils establishing these contradictory properties of Christ for us to impute any sort of sophisticated logical understanding to the church fathers. What sort of logic did the conciliar fathers know? That's a question for history and historians, and one that would take me out of the scope and space of this paper to pursue. Instead, I'll address a slightly different question, "what sort of logic could the conciliar fathers have known?" Until the developments of the $12^{\text {th }}$ century, the broad answer to this

wants to identify with logic (and even when a general concept of "following from" was articulated, this was still but a component of logic, not logic in its entirety). 
question is "Aristotle's Prior Analytics and De Interpretation, with some of the Stoics thrown in; that is, the syllogistic, a system of logic which very narrowly prescribes what counts as an argument and what follows from"; even Boethius's commentaries post-date the earliest ecumenical councils. None of the complex intricacies of reasoning that Beall attributes to the Church Fathers later in his paper (cf. his response to Objection 2, that his proposal is "hermeneutically suspect") are plausible, but instead reflect an anachronistic approach founded on two assumptions: (1) that "logic" or even "consequence" was a relevant notion at the time these theologians were articulating their claims, and (2) that this logic was identifiable with what we call logic nowadays (or, more narrowly, with how logic is defined in the context of Beall's paper).

Neither of these assumptions are plausible. The more likely reason that the conciliar fathers did not flag their special usage of terms is not because they intended ordinary entailment relations to hold but because they didn't even conceive that there could be something like entailment relations. Even if they did know their Aristotle, there simply is nothing that corresponds to explosion in the Aristotelian syllogistic, ${ }^{3}$ and the idea that there was some well-known/well-understood concept of 'entailment' that existed apart from the syllogistic is simply unsupportable.

What you do get, though, in Aristotle, are views on the notion of contradiction and contradictory opposition which are relevant here, and which we explore in the next section.

\section{What is a contradiction?}

The central conclusion Beall is arguing for is that "Christology is in fact logically contradictory, just as it appears to be" (414). This is certainly quite a bold claim, but it is not clear what, exactly, is meant by it. In the early parts of Beall's paper, "logically contradictory" is used in the way it is ordinarily used by logicians when they use it without further specification-logically contradictory according to the rules of classical logic. However, after FDE has been introduced, it is no longer clear what counts as "logically contradictory" according to FDE.

In this section, I want to explore different ways in which "contradiction" and "(logically) contradictory" can be defined, formally and informally, as well as how these ways are manifested in Beall's paper.

The first systematic account of contradiction in western philosophy is found in Aristotle, who discusses contradiction and non-contradiction in a variety of places, including the Metaphysics, On Interpretation, and the Posterior Analytics (see Gottlieb 2015). The most detailed discussion is in the Metaphysics, in the context of what is now known as the law or principle of non-contradiction. Lukasiewicz identifies three different ways that Aristotle formulates the law of non-contradiction, (a) ontological, (b) logical, and (c) psychological, all in Metaphysics $\Gamma$ (Lukasiewicz 1971, 487):

\footnotetext{
${ }^{3}$ Though the use of reductio ad absurdem to reduce Baroco and Bocardo to Barbara contains the germ of EFQ.
} 
(a) It is impossible that the same thing belong and not belong to the same thing at the same time and in the same respect (Met. $\Gamma$ 3. 1005b 19, 20.)

(b) The most certain of all basic principles is that contradictory propositions are not true simultaneously (Met. $\Gamma$ 6. $1011 \mathrm{~b} 13,14$.)

(c) No one can believe that the same thing can (at the same time) be and not be $($ Met. $\Gamma$ 3. 1005b 23, 24.)

Lukasiewicz points out that "None of the three formulations of the principle of contradiction is identical in meaning with the others" (489), and Couvalis $(2009,37)$ claims that Aristotle does not think that either (b) or (c) are the fundamental versions of the principle, only (a) is. However, "the logical formulation seems to be for Aristotle logically equivalent to the ontological formulation" (Lukasiewicz 1971, 489), due to the correspondence between propositions and facts about the world, so even if it is not the most fundamental version of the law, we can still concentrate on it, rather than the ontological formulation which underpins it, as it is logic that interests us most here.

However, whichever version of the law we adopt, it still remains that-a law, and not a definition. The law governs the behavior of contradictory propositions-if two propositions are contradictory (to each other), then they are not true simultaneously-but leaves open the question of what, exactly, contradictory propositions are (that is, it gives us a necessary, but not sufficient condition). The law cannot be taken as a definition of contradictory propositions because defining contradictory propositions as those which are not true simultaneously is incomplete, as the definition would lack the other property traditionally ascribed to contradictory propositions, namely, that they are also not simultaneously false. That is, we need to be able to distinguish contradictory pairs from contrary pairs.

As a result, even though Metaphysics is widely agreed to be the place where the most detailed discussions (and arguments in support) of the principle of noncontradiction can be found in Aristotle, we must look elsewhere for a definition of 'contradiction', namely, in the De Interpretatione:

An affirmation is a statement affirming something of something, a negation is a statement denying something of something. ... It is clear that for every affirmation there is an opposite negation, and for every negation there is an opposite affirmation.... Let us call an affirmation and a negation which are opposite a contradiction (17a25-35).

There are two ways that this definition can be understood: It can be understood as operating at a syntactic level, where "affirmation" and "negation" are identifiable on the basis of their syntactic properties (for instance, whether or not a negation is included, or whether the total number of negations is odd, rather than even). However, the notion of opposition involved is not one of syntactic structure but one of truth value. In the Categories, Aristotle says that in the case of the opposition between contradictories, 
and in this case only, it is necessary for the one to be true and the other false $(13 b 2-3)$.

That is, for Aristotle, contradiction is fundamentally about opposition in truth value: If two contradictory opposites are such that one must always be true and the other false (that is, if contradictory opposites satisfy the principle of non-contradiction, in its logical formulation, stated above, along with its correlated principle, the law of excluded middle), then "a contradiction", namely the conjunction of two contradictory opposites, will always be false (assuming that the truth of a conjunction requires the truth of all of its conjuncts).

The problem is that as soon as one admits of a truth value option other than 'true' and 'false', Aristotle's notion of contradictory opposition is no longer straightforwardly applicable. For "no third type [of statement] is possible because of all four types of opposition [in Aristotle] the one of 'affirmation and negation' excludes intermediates" and

of opposites only contradictories admit of no intermediate terms (for contradiction is that kind of opposition in which either of its two terms could be present in anything whatever); and this opposition clearly has not intermediates (Anton 1957, 96).

On the most uncharitable view, this means that as soon as we have more options than just truth and falsity, the notion of contradiction goes out the window. We could also be more charitable and say that as soon as we have more than two options, the notion of contradiction needs to be revised; and if we were to revise it in a way that most closely captures the essence of the Aristotelian notion, then for any one of the two options we would need to select the one that is "most opposite" of it; that is, "true" and "not true" would become contradictory opposites, not "true" and "false", since "true" and "false" are no longer exclusive.

However, this is not what we see Beall doing when he tackles the concept of contradiction. The issue of what counts as a contradiction arises in the ninth objection, concerning the ubiquity of the law of non-contradiction. As Beall notes, this "law' is "notoriously ambiguous", and he offers a variety of ways that it might be precisified (426). Interestingly, none of these ways is the most fundamental way the principle is expressed by Aristotle noted above, namely, the metaphysical version wherein the law of non-contradiction implies exhaustivity: No sentence is both true and false at the same time.

Beall never gives an explicit definition of what he means by 'contradictory'. In some places (e.g., 416), Beall glosses 'contradictory' as 'negation-inconsistent'; this is a technical term d'art of logic which he also does not define or explain. There are two competing definitions of negation-inconsistency, one semantic, and one prooftheoretic. On the semantic conception, a set of sentences (i.e., a theory) $S$ is negationinconsistent if it has at least one model that satisfies both some formula $\varphi$ and its 
negation $\neg \varphi .^{4}$ On the proof-theoretic account, a set of sentences $S$ is negationinconsistent if there is some formula $\varphi$ such that both $\varphi$ and $\neg \varphi$ are theorems of $S .{ }^{5}$ Negation inconsistency is a weaker form of inconsistency than absolute inconsistency, which is when a theory can derive every formula in the language. Given a proof-system that is sound and complete with respect to some classical semantics, ${ }^{6}$ the semantic and the proof-theoretic conceptions of negation-inconsistency collide; when the semantics are non-classical, these two conceptions of negationinconsistency can come apart.

Negation-inconsistent theories in the proof-theoretic sense are absolutely inconsistent in the presence of a rule such as ex contradictione sequitur quodlibet (ECQ): 7,8

$$
\frac{\varphi \neg \varphi}{\psi}
$$

as one can then take the theorem $\varphi$ whose negation is $\neg \varphi$ is also a theorem and use ECQ to derive every formula. The converse is trivially true; any absolutely inconsistent theory is also negation-inconsistent, whether the system contains ECQ or not.

While Beall does not give a precise definition of 'contradictory', beyond 'negation-inconsistent', he does define 'contradiction'. Beall's definition of a contradiction is one that is syntactic, anything that is of the form "It is true that $p$ and it is false that $p$ " for some proposition $p$, that is, the conjunction of the assertion of the truth of a sentence along with the assertion of the falsity of that very same sentence. (The use of the definition "the logical conjunction of a sentence and its logical negation" occurs on 416). But as we've just seen in discussing negation-inconsistency, this syntactic notion of a contradiction is not the only possible one: and indeed, historically it has never been the primary one. Following Aristotle, "contradiction" is more fundamentally a primarily semantic concept, with the syntactic notion of contradiction being dependent or parasitic on the semantic notion.

This issue of whether 'a contradiction' or 'contradictory' is a semantic, syntactic, or proof-theoretic notion comes up again in Beall's response to Objection 1, that the proposal is "historically suspect"; his evidence for this is a quote of a quote of Leo the Great who argued that "Jesus could be both impassible and passible at the same time without there being any contradiction" (emphasis Beall's). If in the context

\footnotetext{
${ }^{4}$ The semantic conception, so defined, can be found in, inter alia, Marcos 2005. Note that even the semantic definition relies on a syntactic component, namely the idea of the negation of a formula being identified with the same formula with a $\urcorner$ prefixed to it.

${ }^{5}$ Sometimes the proof-theoretic account is defined as the presence of $\varphi \wedge \neg \varphi$ in a theory $S$ for some wff $\varphi$ (e.g., in Robles 2008, 57). This definition is equivalent to the one we have given when the theories in question are closed under conjunction introduction and conjunction elimination, or closed under modus ponens and containing the axiom $\varphi \rightarrow(\neg \varphi \rightarrow \psi)$.

${ }^{6}$ That is, where every sentence has exactly one truth value, either true or false.

7 This result is due to Post in the 1920's (see Woods 2018, 177).

${ }^{8}$ Note that even though this rule has a Latin name, this name is not medieval. The usual medieval description of the rule was ex impossibile sequitur quodlibet. The distinction between contradictions and impossibilities is one we'll return to below.
} 
of FDE, a contradiction is defined to be something that is both at least true and at least false at the same time, then Jesus's being both impassible and passible would indeed not occur without contradiction-assuming, of course, that being in the extension of 'impassible' implies being in the antiextension of 'passible'.

Beall's reply, quite rightly, is to

distinguish two senses of 'contradiction', one being a sentence which is the logical conjunction of a sentence and its logical negation, and the other being an 'explosive sentence', a sentence that, according to a theory's consequence or entailment relation, entails every sentence (of the language of the theory) (419).

The first sense of contradiction is the syntactic one: Any sentence conjoined to its own negation is a contradiction. (This approach to defining 'contradiction' is in keeping with Beall's regular insistence that logic and logical consequence be a matter of form-though recall the issue noted above about how he doesn't take that syntactic principle seriously when defining logical consequence.) Taking 'impassible' to be the negation of 'passible', then "Jesus is both passible and impassible at the same time" can be rewritten into a syntactic contradiction, and thus on this notion of contradiction, Leo's statement cannot be maintained.

The second sense he distinguishes is semantic, defined in terms of the truth value(s) the sentence has, as one that logically entails other sentences. Such sentences will be ones which can never be true (for all-and only-such sentences will entail every sentence in a theory). But since we haven't yet been told what counts as logical consequence or entailment on the FDE account, it is not clear that "Jesus is both passible and impassible at the same time" is not a contradiction on this sense.

On a classical account of logic, everything that is a contradiction in the first sense is also a contradiction in the second sense, as noted above; it is only on a subclassical account of logic that these two senses can be fruitfully distinguished. Beall says that it is the first sense which "is the one involved in the proposed Contradictory Christology" (419). The problem is that once we change the underlying semantic notions, it is no longer the case that everything of the first type is also of the second type, so we are left with the question of why is it that it is the first type, the syntactic, that is a contradiction, and not the second type. That is: Why do we say that on a subclassical account of logic, Contradictory Christology is contradictory at all?

This issue of whether we are interested in a semantic-i.e., grounded in truth-conception of inconsistency (and by extension contradictoriness) or what is essentially syntactic-i.e., grounded in sentences and their negations - is at the heart of my complaint concerning Beall's account of contradiction. These two approaches coincide in classical contexts. Once the classical principles of exhaustion and exclusion are dropped, a clear definition of "contradiction", whether semantic or syntactic, needs to be given: "negation-inconsistent" without further explication is not sufficient.

Under a semantic approach, contradictions cannot ever be true, and two sentences are a pair of contradictory opposites if one of them being a certain truth value implies that the other cannot have that truth value, and vice versa. Since $\varphi$ and 
$\neg \varphi$ are contradictory opposites on classical semantics, we can say that sentences of the syntactic form $\varphi \wedge \neg \varphi$ turn out to be contradictions, because their truth conditions are such that they will never be true; but there are other sentences which are also contradictory that don't have this form, for example, $\neg(\varphi \vee \neg \varphi)$. Thus, a semantic approach is more general than a syntactic one.

Again, once the classical principles of exhaustion and exclusion are dropped, we must ask why it is that "It is true that $p$ and it is false that $p$ " are taken as contradictory opposites, as opposed to "It is true that $p$ and it is not true that $p$." It is easy to be lulled into a false sense of security thinking that the former captures "genuine" or "real" contradictoriness, rather than the latter, when in fact, it is the latter that genuinely opposes two claims; only in the presence of exclusion and exhaustion does the latter collapse into the former.

The issue is that when the semantic concepts of truth and falsity are redefined (so that "at least true" plays the role of 'true' and "at least false" plays the role of 'false'), these definitions have to propagate down the through the rest of the semantic concepts, including that of contradiction. If we retain the semantic conception of contradiction, then by definition there is no such thing as a true contradiction: A contradiction is defined to be that which is never true. If we redefine truth and falsity so that they are no longer opposed, then the contradictory of "it is true that $p$ " is not going to be "it is false that $p$ " but rather "it is not true that $p$ ".

Now, I'm sympathetic to the view that adopting this semantic conception of contradiction might seem to be question begging against Beall's position, and that I should try to engage on the syntactic level, as he defines contradiction. But even then, the semantic background cannot be wholly escaped.

If one wanted to retain a syntactic account of contradiction, the definition still needs to be revised so that it adequately captures the genuine contradictoriness of contradictions: If 'false' is no longer contradictorially opposed to 'true', then "It is true that $p$ and it is false that $p$ " no longer genuinely represents a contradiction (this is a different claim from what Beall is making, which is that this is a contradiction, but one that at least in some cases can be true). A genuine syntactic contradiction would be of the form "It is at least true that $p$ and it is not at least true that $p$ " (only a slight variant from the revised semantic definition we can two paragraphs earlier). This has the correct semantic outcome-it is never even at least true-and retains the needed opposition between true and non-truth (it is an accident of classical logic that falsity turns out to coincide with non-truth; but if we are going to reject the exhaustion and exclusivity properties of classical logic, then we have to also reject the idea that falsity is opposed to truth).

Even if one is not persuaded by the preceding, there is also evidence that Beall's account of contradiction is too narrow even according to his own views. For instance, in $\S 4.2$, he discusses the Liar paradox:

$\checkmark$ The ticked sentence is false.

and says that this is a "prima facie contradiction": But it does not have the right syntactic form, and so, taking Beall's definition of contradiction at face value, this 
shouldn't be analysed as a contradiction. It appears that there must be something else at play in the conception of contradiction that Beall is trying to capture or refer to.

When Beall says that the tenets of Christology are contradictory, I suspect that what he means is that they are contradictory in the semantic sense, in that they are both "(at least) true" and "(at least) false" at the same time (i.e., in the same model(s)). But as we've pointed out above, once we revise the notions of truth and falsity, as Beall does in adopting FDE, it is no longer clear that something being both "at least true" and "at least false" at the same time is contradictory, at least, not in the Aristotelian sense of 'contradictory' (cannot both be true at the same time and cannot both be false at the same time): The contradictory of "at least true" is not "at least false" but "not at least true". The result is that either Christology is not genuinely contradictory on the account of logical consequence that Beall advocates, or if it is, then switching to FDE doesn't help solve anything.

\section{Where to go from here}

I don't want to end on such a negative note, though, because I think that the kernel of what Beall is trying to do in his paper is correct, even though it doesn't quite work. The reason I think it's correct is because it's one that is at the heart of a number of systematic approaches to theological paradoxes and puzzles throughout the history of logic. The difference is that instead of focusing on the notion of contradiction, medieval logicians focused instead on possibility and impossibility. In this section I'd like to return to some of these historical solutions, and show how they relate to what we said about the development of a general notion of logical consequence from the $12^{\text {th }}$ century on in $\S 2$.

Early medieval work on the general theoretical concept of "logical consequence" tends to be rooted in Aristotelian principles, even if not necessarily Aristotelian logic. Two commonly cited principles are that "from the possible nothing impossible follows" and the possible is "that which is not necessary but, being assumed, results in nothing impossible". 9,10 The first of these is a necessary claim about logical consequence, but not a sufficient one, and the second is a definition of a term in the former. When these two principles are combined with the imperative that

\footnotetext{
${ }^{9}$ For instance, in the anonymous treatise discussed below (cf. fn. 11), the author says that Just as we say that something possible must be conceded in order to see what follows from it, similarly we have it from Aristotle that something impossible must be conceded in order to see what happens then" (Anonymous 2001,217); sicuti enim nos dicimus quod possibile est concedendum ut videatur quid inde sequitur, similiter habemus ab Aristotile quod impossibile est concedendum ut videtur quid inde accidat (de Rijk 1974, 117).
}

Because it is possible to understand something impossible, it is also possible to posit something impossible, and this is the author's justification for considering positio impossibilis as a legitimate genre.

${ }_{10}$ Though various authors attribute this principle to Aristotle, in truth no such principle has been identified in Aristotle; the most similar statement is found in Boethius's De Hypotheticis Syllogismis, attributed to Eudemus. See Martin 2001, 64. 
"something possible must be conceded in order to see what follows from it", we then have a mechanism that we can use to help determine what follows from what, and therefore to step closer to a general account of logical consequence. In fact, perhaps the easiest way to understand what is going on in early treatises in the otherwise mysterious genre of obligationes disputations is that they are attempts to work out a rigorous notion of logical consequence that respects these principles.

Note here the central role that possibility and impossibility play. These are two notions that greatly exercised medieval logicians in large part because of their connections with theological puzzles. There are many things which seem impossible (or are impossible given the natural order of things), but which in the presence of God's omnipotence are rendered no longer impossible. This led medieval philosophers to distinguish between different types (or grades) of possibilities and impossibilities, with some impossibilities being "more impossible" (taking this loosely!) than others. For instance, certain things are impossible according to the laws of nature, but yet nevertheless can still be understood or imagined. That which is impossible according to nature but possible according to imagination can be said to be "less impossible" than something which is impossible both according to nature and according to imagination.

Early treatises argue that it should be possible to reason from impossibilities in a principled and non-trivial way. As the anonymous author of a treatise on reasoning from impossible statements ${ }^{11}$ puts it:

something impossible can be understood, for he [Aristotle] talks about taking a fish from the water so that nothing assumes its place-which is impossible. Hence it is possible to understand something impossible. Therefore, since we can posit that that which we can understand, it is clear that an impossible positio must be accepted and something impossible must be conceded (Anonymous 2001, 217). ${ }^{12}$

The fact that it is possible to maintain a negation-inconsistent theory without collapsing into triviality (absolute inconsistency) was well-known to the later medieval logicians, who in the $12^{\text {th }}$ century questioned the legitimacy of both the principles ex impossibile quodlibet and ad necessarium quodlibet, with the Parvipontanae ${ }^{13}$ accepting the principles while Peter Abelard and the so-called Nominales rejected them. The anonymous treatise quoted above singles out the "Adamite" thesis by name in order to identify it as unacceptable in the context of admitting impossible premises:

\footnotetext{
11 This treatise is found in MS CLM 14 458, edited and dated to the first half of the thirteenth century by de Rijk (1974), who calls it Tractatus Emmeranus de Positio Impossibilis. An English translation appears in Anonymous 2001.

12 Quod impossibile potest intellegi. Dicit enim quod piscis extrahatur ab aqua, ita quod nichil subintret locum eius, - quod est impossibile-, ita impossibile potest intelligi. Ergo cum possumus ponere illud quod possimus intelligere, patet quod impossibilis positio est recipienda et impossibile est concedendum (de Rijk 1974, 118).

13 The followers of Adam de Petit-Pont (Adam Parvipontanus, Adam of Balsham), who taught in Paris in the middle of the $12^{\text {th }}$ century. See Minio-Paluello 1956.
} 
And we should note that in this question everything does not follow from an impossible obligation. Thus, in this question one must not concede the consequence of the Adamites-namely that from the impossible anything follows (218). ${ }^{14}$

Note the use of "impossible" rather than "contradictory" here: One place where medieval logicians were ahead of much of their modern counterparts was in the recognition of different types, or grades, of impossibility, some of which are more pathological than others (the most pathological being the strictly, syntactically, contradictory, the conjunction of a sentence and its negation).

These different grades of possibility and impossibility were intimately tied to theological questions, specifically questions concerning God's abilities, such as whether he could make a goat-stag (an animal that participates essentially in two different species), a metaphysical impossibility.

Their approach to the problem of theological impossibilities was therefore twofold: to recognize that not all impossibilities are contradictions and then, in the presence of strict syntactic contradictions-the conjunction of a sentence and its negation-to weaken the inference rules so as to prevent trivialization.

Two things are remarkable about this approach. The first is how much it resembles the strategy that Beall himself uses in his paper, by identifying ways in which we can accept apparent "contradictions" without trivializing logic. The second is how the medieval approach avoids some of the concerns that we've raised with Beall's tactics: Whereas Beall focuses on the notion of contradiction, medieval authors separated contradictions and impossibilities, admitting that the former are always the latter, but the latter are not always the former. We can than develop rules of entailment wherein not everything follows from an impossibility (removing that route to trivialization) and only the conjunction of genuine contradictory opposites entails everything. Combining this latter prong with the fact that in a non-binaryvalued logic, "truth" is no longer contradictorially opposed to "falsity", we can then take full advantage of all the benefits that FDE gives us.

14 Et notandum quod in hac questione ex obligatione impossibili non sequitur quidlibet. Unde consequentia Adamitorum non est concedenda in hac questione, scilicet quod ex impossibili sequitur quidlibet (de Rijk 1974, 118). 


\section{Bibliography}

Anonymous. 2001. "The Emmeran treatise on impossible Positio." In Medieval Formal Logic, edited by M. Yrjönsuuri. Kluwer Academic Publishers. 217-223.

Anton, John Peter. 1957. Aristotle's Theory of Contrariety. Routledge and Kegan Paul.

Aristotle. 1963. Categories and De Interpretatione, edited by J. N. Ackrill. Clarendon.

Bacon, Roger. 2009. The Art and Science of Logic, translated by Thomas S. Maloney. Pontifical Institute of Medieval Studies.

Couvalis, George. "Aristotle on non-contradiction." 2009. In Greek Research in Australia: Proceedings of the Eighth Biennial International Conference of Greek Studies, Flinders University, June 2009, edited by M. Rossetto, M. Tsianikas, G. Couvalis, and M. Palaktsoglou. Flinders University Department of LanguagesModern Greek. 36-43.

de Rijk, L. M. 1974. "Some thirteenth century tracts on the game of obligation." Vivarium 12: 94-123.

Gottlieb, Paula. 2015. "Aristotle on non-contradiction." In Stanford Encyclopedia of Philosophy, edited by Edward N. Zalta. https://plato.stanford. edu/archives/sum2015/entries/aristotle-noncontradiction.

Grant, Edward. 1979. "The condemnation of 1277, God's absolute power, and physical thought in the late Middle Ages." Viator 10: 211-244.

. 1996. The Foundations of Modern Science in the Middle Ages. Cambridge University Press.

Lukasiewicz, Jan. 1971. "On the principle of contradiction in Aristotle." Translated by Vernon Wedin. Review of Metaphysics 24 (3): 485-509.

Marcos, João. 2005. "Nearly every normal modal logic is paranormal." Logique et Analyse 48 (189/192): 279-300.

Martin, Christopher J. 2001. “Obligations and liars." In Medieval Formal Logic, edited by M. Yurjönsuuri. Kluwer Academic Publishers. 63-94.

Minio-Paluello, Lorenzo (editor). 1956. Twelfth Century Logic: Texts and Studies. Vol. 1. Edizioni di Storia e Letteratura.

Robles, Gemma. 2008. "Extensions of the basic constructive logic for negationinconsistency BKc4 defined with a falsity constant." Logique et Analyse 51 (201): 57-80. 
Woods, John. 2018. Truth in Fiction: Rethinking Its Logic. Springer. 